\title{
VIOLÊNCIA DE GÊNERO: PARADOXOS NA ATENÇÃO A HOMENS ${ }^{1}$
}

\author{
Benedito Medrado* \\ Anna Renata Lemos" \\ Jullyane Brasilino ${ }^{\circledast}$
}

\begin{abstract}
RESUMO. Este trabalho tem por objetivo analisar, a partir de uma perspectiva psicossocial, posicionamentos e argumentos construídos por profissionais que atuam na rede de enfrentamento à violência contra as mulheres acerca das possibilidades e modalidades de atenção aos homens denunciados. Para tanto, foram realizadas entrevistas com 55 profissionais que atuam em serviços diretamente relacionados à denúncia e acompanhamento de casos de violência na Região Metropolitana de Recife. A metodologia de análise foi de natureza qualitativa, tomando por base a análise de conteúdo categorial. Os resultados evidenciam uma ordem de posicionamentos organizada nos eixos punição, prevenção e medidas assistenciais, os quais remetem a uma polissemia de sentidos sobre violência e a um complexo jogo de argumentos. Diante disso, destaca-se a necessidade de ampliar estudos referentes a homens envolvidos em episódios de violência contra a mulher e de investir em processos de sensibilização de gênero e ressignificação simbólica dos próprios profissionais.
\end{abstract}

Palavras-chave: Masculinidade; gênero; conflito conjugal.

\section{GENDER VIOLENCE: PARADOXES ON SUPPORT TO PERPETRATORS}

\begin{abstract}
This work aims to analyze, from a psychosocial perspective, positions and arguments built by professionals working in the network to deal with violence against women, about the possibilities and modalities of attention to the men reported. Interviews were conducted with 55 professionals working in services directly related to the complaint and monitoring cases of violence in the metropolitan area of Recife. The analysis methodology was qualitative, based on the analysis of categorical content. The results show an order of positions organized in three axes (punishment, prevention and support measures) that refer to a polysemy of meanings on violence and a complex set of arguments. The study highlights the need to broaden studies focused on men involved in violence episodes against women as well as investments in processes of gender awareness and symbolic reinterpretation of the professionals themselves.
\end{abstract}

Key words: Masculinity; gender; marital conflict.

\section{VIOLENCIA DE GÉNERO: PARADOJAS EN LA ATENCIÓN A LOS MALTRATADORES}

RESUMEN. Esta investigación tiene el objetivo de analizar los posicionamientos y argumentos construidos por profesionales que trabajan en la red de servicios de enfrentamiento a la violencia contra las mujeres, en Recife, Nordeste de Brasil, sobre las posibilidades y las modalidades de atención a los hombres acusados de violencia de género. Se han realizado entrevistas con 55 profesionales que actúan en servicios directamente relacionados a la denuncia y seguimiento de los casos de violencia doméstica y familiar contra mujeres en la Región Metropolitana de Recife. La metodología de análisis fue cualitativa, basada en el análisis de contenido, del tipo categorial. Los resultados evidencian un orden de posicionamientos organizado en tres ejes (punición, prevención y medidas asistenciales) que remeten a una polisemia de sentidos sobre la violencia y a un complejo juego de argumentos. Se destaca la necesidad de ampliar los estudios dirigidos a los hombres involucrados en situacioes de violencia contra mujeres e inversiones en procesos de sensibilización de género y resignificación simbólica de los propios profesionales.

Palabras-clave: Masculinidad; género; conflicto marital.

Apoio: CNPq.

Doutor em Psicologia (Psicologia Social) pela Pontifícia Universidade Católica de São Paulo. Professor Adjunto da Universidade Federal de Pernambuco, Brasil.

II Mestre em Psicologia pelo Programa de Pós-Graduação em Psicologia da Universidade Federal de Pernambuco. Gestora de saúde da Secretaria Estadual de Saúde de Pernambuco, Brasil.

x Mestre em Psicologia pelo Programa de Pós-Graduação em Psicologia pela Universidade Federal de Pernambuco, Brasil. 
Este artigo apresenta parte dos resultados de análises produzidas no contexto de um projeto de pesquisa multicêntrica sobre atenção a homens autores de violência de gênero desenvolvido pelo Núcleo de Pesquisas em Gênero e Masculinidades da Universidade Federal de Pernambuco, em parceria com a organização não governamental Instituto PAPAI, com apoio do Ministério da Saúde/CNPq.

As informações aqui apresentadas compreendem um recorte da pesquisa mais ampla e têm como objetivo analisar posicionamentos e argumentos construídos por profissionais que atuam na rede de enfrentamento à violência contra as mulheres em Recife acerca da atenção aos homens denunciados por agressão por suas companheiras.

\section{BREVE CONTEXTUALIZAÇÃO}

Este é um tema ainda "emergente" no campo das Ciências Humanas, Sociais e da Saúde Pública, tanto do ponto de vista da produção acadêmica como no que concerne às intervenções referentes a homens, especialmente no Brasil (Arilha, 2008; Schraiber \& D'oliveira, 2008; Schraiber, D'Oliveira \& Couto, 2009; Schraiber, D’Oliveira, Falcão \& Figueiredo, 2005; Hanada, D'oliveira \& Schraiber, 2010; Schraiber, Barros \& Castilho, 2010).

Por certo, o campo de estudos sobre violência contra a mulher tem contribuído para dar visibilidade a esse fenômeno dos pontos de vista teórico e éticopolítico. Esses estudos não apenas produziram conhecimentos sobre o tema, mas também contribuíram com os esforços de legitimação da violência contra as mulheres como grave problema de saúde pública e direitos humanos que merece ser abordado a partir de uma rede de serviços que se configure em uma perspectiva interdisciplinar, dada a complexidade do problema. Como ressaltam Schraiber, D’Oliveira e Couto (2009),

Reconhecendo-se a complexidade desse objeto, que articula domínios médico, sanitário, social e cultural, devemos considerar a insuficiência de disciplinas isoladas para dar conta de sua apreensão e transformação. A colaboração interdisciplinar deve assim dirigir-se a esforços como os que seguem (p. 1025).

Além disso, há um descompasso da atuação de algumas instituições e profissionais em relação às demandas das mulheres que buscam esses serviços. Kiss, Scraiber e D'Oliveira (2007) adotam como exemplo a delegacia, que aborda os casos de violência do ponto de vista legal, de acordo com as disposições da lei federal a respeito do assunto, minimizando as dimensões subjetivas dos atores envolvidos, que divergem bastante em forma e conteúdo das definições jurídico-policiais, o que se reflete na eficácia desta atuação. Apontam ainda que geralmente existem desajustes entre a linguagem utilizada pela mulher que vivencia a situação de violência e a usada pelo profissional a quem essa mulher recorre (Kiss et al., 2007).

Não obstante, há avanços e conquistas no âmbito do enfrentamento público à violência doméstica e familiar contra a mulher. A mais recente e de maior impacto foi a aprovação e implementação progressiva da Lei 11.340 - conhecida como Lei Maria da Penha -, sancionada em 07 de agosto de 2006 pelo então Presidente da República Luiz Inácio Lula da Silva. Esta lei cria mecanismos para coibir e prevenir a violência doméstica e familiar contra a mulher, atendendo a recomendação da Comissão Interamericana de Direitos Humanos da Organização dos Estados Americanos.

É importante ressaltar que a Lei, de certo modo, reconhece que para intervir no contexto da violência doméstica e familiar contra as mulheres a partir da perspectiva de gênero é preciso implementar ações que possam também incluir os homens.

Aqui estamos compreendendo gênero a partir da leitura feminista proposta por Medrado \& Lyra (2008), para os quais adotar a perspectiva de gênero não implica necessariamente produzir leituras críticas sobre diferenças e desigualdades. A leitura feminista de gênero pode, por outro lado, contribuir para orientar os serviços destinados a superar dispositivos de iniquidade sem que para isso sejam necessárias novas especialidades, espaços ou medicamentos específicos.

Como destacam Medrado \& Méllo (2008), as políticas propostas para o enfrentamento à violência contra a mulher apresentam várias lacunas, entre elas: 1) não fazem nenhuma alusão a trabalhos de prevenção com a população masculina e 2) não apresentam uma definição clara sobre a estrutura e organização dos centros de atendimento aos agressores, cuja finalidade, conforme a Lei, seria "educação e reabilitação" (art. 35) ou "recuperação ou reeducação" (art. 45).

Neste contexto, torna-se necessário investir amplamente em discussões sobre a atenção aos chamados "agressores", com vistas a uma implementação integral da Lei como estratégia eficaz de enfrentamento à violência contra a mulher que, 
indo além dos binômios ofendida-agressor e proteçãopunição, remeta à dimensão relacional do conceito de gênero.

Como ressaltam Debert e Gregori (2008), é importante reconhecer a trajetória do debate sobre violência contra a mulher em suas bases feministas e em sua leitura relacional de gênero, de modo a "empreender uma reflexão sobre os efeitos e os limites das articulações analíticas entre crime, violência e relações marcadas pelas diferenças de gênero" (p. 165).

Neste sentido, a presente pesquisa teve como foco analisar como os profissionais que atuam na rede de enfrentamento à violência contra a mulher em Recife negociam sentidos sobre a atenção a homens autores de violência, denunciados no contexto da Lei Maria da Penha. Mais especificamente, busca identificar como esses profissionais se posicionam em relação à possibilidade de serviços específicos voltados aos chamados "agressores" e que argumentos sustentam suas posições. A leitura crítica sobre esses posicionamentos e argumentos pode contribuir para o desenho de uma proposta de política pública mais eficaz para esta população, superando barreiras culturais, institucionais e interpessoais.

Definimos "posicionamentos" tendo por base as contribuições de Davies e Harré (1990), segundo os quais estamos constantemente em jogos discursivos, construindo ao mesmo tempo versões sobre a realidade e sobre nós mesmos. Estudar os repertórios discursivos (Spink \& Medrado, 1999) que sustentam esses jogos de posicionamento é uma forma de nos aproximarmos do cotidiano dessas pessoas e identificar suas práticas discursivas.

A noção de práticas discursivas aqui adotada fundamenta-se na compreensão da linguagem como ação que produz consequências (Spink \& Medrado, 1999). Assim, nossa tarefa consiste em estudar a dimensão performática do uso da linguagem, trabalhando com consequências amplas e nem sempre intencionais. Num movimento constante de construção e negociação de argumentos, em um exercício retórico (Billig, 1987), quando falamos, estamos invariavelmente realizando ações, produzindo um jogo de posicionamentos que nos orienta em ações cotidianas.

\section{MÉTODO}

A elaboração dos instrumentos, a pesquisa de campo e os processos de análise para esta pesquisa envolveram uma equipe de pesquisadores e pesquisadoras, incluindo estudantes de graduação e pós-graduação das áreas da psicologia, serviço social e medicina. Todas as estratégias de pesquisa foram construídas e negociadas em grupo, envolvendo tanto atividades de observação como a realização de entrevistas semiestruturadas.

Para identificar os/as entrevistados/as, partimos originalmente da leitura de documentos (especialmente guias de serviços impressos ou disponíveis via internet) produzidos pela gestão municipal (Coordenadoria da Mulher) e federal (Secretaria Especial de Políticas para as Mulheres), bem como de redes (Fórum de Mulheres de Pernambuco), organizações não governamentais e grupos da sociedade civil. Foram também contatados informantes específicos que atuam no campo. Com base nas informações obtidas, foram identificadas todas as instituições que compunham a assim definida "rede de atenção, prevenção, assistência e combate à violência contra a mulher na cidade de Recife", gerando um total de 38 instituições, conforme tabela a seguir.

Tabela 1. Distribuição das Instituições que Atuam na Rede de Enfrentamento à Violência Contra as Mulheres em Recife, Por Campos de Atuação.

\begin{tabular}{lc}
\hline \multicolumn{1}{c}{ Campos de atuação } & Número de instituições \\
\hline Justiça e Segurança Pública & 06 \\
Órgãos de gestão governamental & 02 \\
Serviços de denúncia & 02 \\
Espaços de organização política & 15 \\
Espaço acadêmico & 02 \\
Serviços de Assistência à Mulher & 11 \\
\hline \multicolumn{1}{c}{ Número total de instituições } & $\mathbf{3 8}$ \\
\hline
\end{tabular}

Essas instituições foram contatadas inicialmente por telefone e posteriormente por meio de visitas in loco. Mediante carta de anuência firmada pelos representantes legais das instituições, foi possível a autorização e identificação de profissionais para as entrevistas, as quais foram conduzidas a partir de um roteiro semiestruturado cuja estrutura privilegiava narrativas sobre histórico profissional, valores e opiniões desses profissionais sobre a atenção aos homens no contexto do enfrentamento à violência contra as mulheres.

A escolha dos/as entrevistados/as se deu a partir de visitas às instituições e da indicação de outros profissionais, levando-se em conta a importância de sua atuação. As entrevistas eram gravadas em áudio, depois de os participantes terem lido e assinado um termo de consentimento livre e esclarecido, e foram conduzidas por dois entrevistadores, um dos quais era 
o que "conduzia" as narrativas, podendo o segundo entrevistador intervir sempre que houvesse necessidade. $\mathrm{O}$ anonimato dos participantes também foi garantido, sendo seus nomes substituídos por códigos, para evitar em qualquer hipótese sua identificação.

No total, foram realizadas entrevistas com 55 profissionais, com idades entre 18 e 63 anos, dos quais 11 eram do sexo masculino e 44 do sexo feminino. Quanto ao nível de escolaridade, 49 profissionais haviam concluído o ensino superior, onze tinham mestrado ou doutorado concluído ou em andamento. Quatro profissionais tinham o ensino superior incompleto e dois tinham nível médio de escolarização. O grupo entrevistado apresentava uma grande diversidade de formação (ciências contábeis, comunicação social, jornalismo, sociologia, medicina, etc.), mas entre os formados, a grande maioria tinha formação em Psicologia (11), Direito (09) e Serviço Social (06).

Vale ressaltar que esta é uma pesquisa de natureza qualitativa, portanto não tem o compromisso com a generalização ou com uma visão de ciência como espelho da natureza (Rorty, 1979). Ao invés de nos preocuparmos com respostas finalistas às nossas inquietações, nossos esforços se concentraram em produzir efeitos relevantes com as informações ora trazidas, quais sejam, a possibilidade de fomentar políticas públicas de atenção a homens autores de violência contra a mulher. Como bem destaca Cecília Minayo (1999), a metodologia qualitativa "trabalha com um universo de significados, motivos, aspirações, crenças, valores e atitudes, o que corresponde a um espaço mais profundo das relações, dos processos e dos fenômenos que não podem ser reduzidos à operacionalização de variáveis" (p. 21). Neste sentido, "a linguagem, as práticas e as coisas são inseparáveis" (Minayo, 1999, p.24).

A metodologia de análise nesta pesquisa seguiu especialmente a orientação da análise de conteúdo categorial (Bardin, 1977). Assim, foi efetuada uma leitura integral de todas as entrevistas e, a partir de discussão em grupo, identificados focos de análise e as categorias construídas a partir dos termos e expressões empregados pelos/as entrevistados/as e trechos do diálogo.

\section{RESULTADOS}

Na primeira aproximação às entrevistas, chamounos a atenção a diversidade de formas de nomeação utilizadas para fazer referência às diferentes dimensões desse tipo de violência. Identificamos referências diretas de violência (especialmente em sua dimensão física ou sexual), mas também termos e expressões que fazem referência à violência verbal, à psicológica, à moral, à patrimonial, à "violação do direito de ir e vir" ou termos e expressões difusos e indefinidos, tais como "confusão", "ambiguidades", "coisa complexa", "problema", "esses atos", etc.

A ordem pública, especialmente a ordem jurídicopenal, é tomada pelos/as entrevistados/as como referência principal para as estratégias de enfretamento. A transformação do privado (ou campo da intimidade) em público (ordem coletiva instituída) é tomada como a estratégia mais adequada de resolução do problema, no sentido de que a forma mais indicada para lidar com a violência é torná-la pública.

Nas falas dos profissionais percebe-se também uma clara dicotomia homem/autor versus mulher/vítima, gerando nomeações nas quais as mulheres são referidas com termos como "agredida", "a parte agredida", “abandonada", "espancadas", "ofendida", "pessoa vítima de violência', "protegida", "submissa", "vítima", etc.

Os homens, por sua vez, são referidos a partir de um conjunto diverso de repertórios discursivos que incluem:

- referência à violência como traço ou marca identitária do homem que a comete ("agressor", "homem agressor", "agressor de mulheres", "agressor doméstico", “desumano", “opressor");

- referência à violência como uma prática, sem necessariamente incorrer em marcações identitárias ("autor do fato", "autores de violência contra a mulher", "homem autor de violência", "homem que cometeu violência");

- marcações de poder ("chefão", "o que manda", "detentor do poder"), ou de criminalidade ("bandido", "criminoso").

Há ainda a referência às marcas culturais como justificativa para o ato, sendo o homem nomeado uma única vez como "vítima de uma construção cultural".

Os argumentos dos/as entrevistados/as, quando interrogados/as sobre a importância e/ou necessidade de atenção aos homens autores de violência contra a mulher, foram organizados em três categorias: punição, prevenção e medidas assistenciais.

No que se refere à categoria punição, observa-se uma frequente referência à privação de liberdade como forma de "castigo" para o "agressor", mas ao mesmo tempo é enfatizada a precariedade do sistema prisional atual oferecido pelos Estados e sua falência enquanto "sistema de ressocialização". Mesmo 
considerando a prisão como forma de punição, de alguma forma os/as entrevistados/as fazem referência a outras medidas de assistência associadas à privação de liberdade. Neste sentido, alguns defendem que os chamados, "agressores" devem, além de ser privados de liberdade, ser submetidos a estratégias que visem à reeducação e transformação. Aqui se faz uma referência, por clara oposição, à Lei 9.099, aplicada por muitos anos (em função de jurisprudência) aos casos de violência contra a mulher, a qual garantia ao autor da violência a possibilidade de medida alternativa (e não complementar) à detenção.

Diferentemente da "prisão como punição", nesses argumentos podemos observar que a punição deve-se mediante a aplicação de penas que estimulem a mudança de comportamento dos autores desse tipo de violência. Para fundamentar suas posições, os profissionais apontam a ineficácia do modelo de punição que atua como castigo, bem como a peculiaridade desse crime contra a mulher e de quem o comete, advogando tratar-se de um crime que possui especificidades e, como tal, exige também respostas específicas.

Além das medidas de punição, aparecem também, com forte ênfase, medidas de prevenção, que são apresentadas de forma complexa. Há referências a processos de "conscientização" dos homens para que percebam que a violência contra a mulher traz prejuízos para todos os envolvidos. Neste sentido são sugeridos grupos de reflexão sobre temas relacionados à equidade de gênero e à violência, a fim de que esses homens "aprendam" a se relacionar a partir de uma cultura não sexista, respeitando os direitos das mulheres.

Entrevistadora: Você conhece algum serviço que faz algum trabalho voltado pra o agressor?

Profissional: Não. Não tem nenhum serviço que trabalhe com isso e é extremamente necessário. É importante ter.

Entrevistadora: Por que seria importante ter?

Profissional: Porque eu acho que, bom, primeiro que tem uma discussão que a gente tem feito no interior da instituição que, claro, a gente tá num foco agora nesse momento com mulheres, etc. e tal, mas os homens também têm uma construção social, eles respondem também a um processo social, de construção social, na qual eles tão inseridos. Então, a gente acredita que o fato de que homens são criados nessa perspectiva de que podem bater em mulher, que podem fazer isso, isso também tem uma influência na vida deles e que é preciso ter algum momento, ter algum espaço que os ajude a desconstruir isso. Ou seja, as pessoas não são más simplesmente porque elas são más, os agressores não são agressores porque eles resolveram um belo dia ser agressores, claro que tem tudo, tem as pessoas que têm suas perversões, tem seus desvios, né, de, de... psicológicos e etc., mas tem toda uma construção social também no universo masculino, que acho que a gente precisa começar a discutir, olhar e aprofundar.

Nesses argumentos os homens são reconhecidos como sujeitos de direitos, mas se apontam possibilidades de conquista de igualdade de direitos entre homens e mulheres, envolvendo vários atores sociais, como família, escola, Estado, poder judiciário, homens e mulheres. Esta categoria analítica indica que os homens foram educados de forma inadequada e se faz necessário educá-los novamente para que não cometam violência.

Nesta perspectiva, articulando argumentos voltados a uma abordagem mais preventiva do problema, alguns/algumas entrevistados/as fazem referência a serviços e políticas nas diversas áreas de justiça, saúde, educação e ONGs como estratégias que deveriam ser empregadas junto aos homens autores de violência, a partir de uma abordagem integral que trabalhe diversos temas dentro de uma perspectiva de gênero.

Os homens aparecem, neste sentido, como sujeitos de necessidades, sendo muitas vezes os serviços e redes disponíveis para as mulheres tomados como parâmetros para projetar o modelo ideal de atenção a eles. Para o reconhecimento da necessidade de políticas públicas que venham a atender aos homens em outros aspectos que não as demandas referentes à violência contra a mulher, esses profissionais defendem ser necessária a conscientização dos homens para a necessidade do cuidado de si e dos outros para, a partir disso, dar início a um processo de mudança que teria como consequência o fim da violência de gênero.

Além disso, são sugeridas medidas preventivas consistentes de processos educativos em geral, seja para crianças e adolescentes seja para homens que não cometeram violência. Tal posição remete à importância da prevenção antecedendo a prática de atos de violência, através de trabalhos de promoção e educação como parte do dia a dia das pessoas, comunidades e grupos, mostrando a preocupação de 
incluir a discussão de gênero no campo da saúde e da educação, com vista a uma verdadeira transformação no cotidiano das relações sociais.

Entre as estratégias assistenciais ou de intervenção direta propostas pelos/as entrevistados/as, destaca-se a referência a programas de atenção psicológica ou psicossocial. Essas propostas incluem $\mathrm{o}$ atendimento individual e o aconselhamento, individual e/ou grupal, serviço que pode ser prestado por um psicólogo/a ou uma equipe multidisciplinar.

Os argumentos para justificar um atendimento psicossocial como estratégia para atuação junto a homens autores de violência geralmente estão baseados na ideia de que a violência é um processo cíclico, referindo-se a pesquisas em que os homens autores de violência relataram ter sido também agredidos ou abusados na infância (Acosta \& Barker, 2003). Os profissionais justificam essa posição afirmando que os homens possivelmente agrediram as mulheres em função de um "trauma" ou da vivência de situações em que a violência esteve presente, negando, assim, a intencionalidade da violência cometida/denunciada. A atenção psicológica seria um meio para chegar à causa de seu comportamento e mudar a situação. Esses argumentos ignoram, por exemplo, o número de homens que quando crianças e adolescentes foram violentados, porém não reproduziram o "modelo" violento do qual foram vítimas.

Em outras falas, alguns comportamentos violentos estão atrelados ao envolvimento do "agressor" com o uso do álcool, sendo necessárias medidas de tratamento nos moldes do trabalho desenvolvido nos chamados Centros para dependentes de álcool e outras drogas.

Entrevistadora: $O$ que você acha que um serviço de atendimento aos homens agressores deveria ter?

Profissional: Deveria ter um setor de pesquisa, pra poder fazer uma avaliação da vida pregressa dele para saber como é que foi, que tivesse oportunidade de dialogar com homens que venceram essa doença, digamos assim né, que eles tivessem esse intercâmbio com homens saudáveis, e com homens, eu acho até como uma coisa como o $A A$, que tivessem passado por isso, que tivessem compreendido $e$ hoje tivessem dando um exemplo, eu acho que valeria a pena essa vivência, não sei qual é o termo que vocês usam em psicologia, como é o $A A$, mesmo passo a passo, "estou há tantos dias sem bater na minha mulher" - tá entendendo? - de troca, pra eles se sentirem que pessoas tinham um comportamento similares e superaram, NE?.

Neste aspecto, os atos e comportamentos violentos praticados pelos homens são considerados uma forma de doença passível de ser tratada por condicionamentos, medicamentos ou outras formas.

Em linhas gerais, os argumentos dos/as entrevistados/as, em relação à importância e/ou necessidade de atenção aos homens autores de violência contra a mulher, podem ser associados a três tipos de proposição:

- medidas punitivas - na forma de prisão ou na forma de reeducação, entendida como pena complementar;

- medidas preventivas - a partir da reeducação como um direito, de políticas públicas para homens ou pela educação de gênero, junto aos mais jovens (como forma de prevenção primária) ou aos que cometeram violência (como forma de evitar reincidência);

- medidas assistenciais - pela via da atenção psicossocial ou a partir de modelo semelhante ao empregado junto a usuários de drogas, especialmente do álcool.

\section{DISCUSSÃO}

Como dito anteriormente, a atenção aos homens autores de violência de gênero é um tema ainda "emergente" no campo das Ciências Humanas, Sociais e da Saúde Pública. Neste sentido, o presente artigo certamente traz muito mais inquietações e provocações do que respostas. Identificamos uma variedade de definições sobre violência contra a mulher nas falas dos/as entrevistado/as. A violência é entendida como um conceito multifacetado e dinâmico que remete a tipologias e determinações distintas, com uma polissemia de definições e significados.

Vale ressaltar que esta pesquisa está inserida no contexto histórico de implementação progressiva da Lei Maria da Penha, a qual prevê não apenas a criação de novas estruturas, mas também de novos padrões conceituais, especialmente a partir da tipificação da violência doméstica e familiar como um crime, com pena e procedimentos específicos, em consonância com a matriz feminista que traz à tona, especialmente a partir da década de 1980, a publicização e consequente politização e criminizalização da violência contra a mulher (Schraiber et al., 2009). A transformação do privado (ou o campo da intimidade) 
em público (ou da ordem coletiva instituída) é tomada como a estratégia mais adequada para a resolução do problema, instaurando-se uma progressiva "judicialização dos conflitos familiares" (Rifiotis, 2004).

Neste processo de implementação da Lei Maria da Penha vários questionamentos sobre seus princípios e sua aplicabilidade estão ainda em discussão, não no sentido de anulá-la, mas de potencializar seus efeitos (Medrado \& Méllo, 2008). Estarmos inseridos neste campo político, neste momento da história, possibilitou-nos identificar tensões, discussões e outros olhares sobre esse fenômeno que apontam para uma gama de possibilidades de estudos a serem ainda desenvolvidos.

Percebemos que, apesar de a maioria dos profissionais se posicionarem favoravelmente à implementação de serviços voltados aos homens, quando questionados sobre como deveriam ser estes serviços, eles demonstraram dificuldades e contradições em seus posicionamentos. Há uma tendência à defesa de medidas punitivas como estratégia para atuação junto aos homens que cometem esse tipo de violência. Tal perspectiva parece apoiar-se em uma visão do homem como algoz e da mulher como vítima, minimizando o aspecto relacional da violência contra a mulher (Gregori, 1993; Mello, Silva \& Caldas, 2009).

Por outro lado, aparecem argumentos em que os atos e comportamentos violentos praticados pelos homens são considerados uma forma de doença passível de ser curada por condicionamentos, medicamentos e tratamentos. Os profissionais fazem referências a vícios e transtornos associando-os diretamente à violência denunciada, o que nos faz pensar em uma "desresponsabilização" dos homens em relação a seus atos e comportamentos.

Por fim, também posicionamentos resistentes e radicais aparecem fortemente nessas entrevistas. Duas das entrevistadas declararam explicitamente a resistência absoluta a qualquer ação com os considerados "agressores". Além disso, por vezes, na observação dos serviços e entidades visitadas, percebeu-se pouca abertura da rede de serviços a uma ação mais ampla, que também possa incluir o homem, sendo muitas vezes emitidas falas como "eu acho importante, mas eu não vou fazer isso. Os outros (e principalmente os próprios homens) que busquem seus caminhos". Essa ideia aparece também na conclusão da tese de doutoramento de Margareth Arilha (2005), quando afirma: "Não se trata de educar os homens, mas de acreditar em um processo de transformação no qual muita energia deveria ser urgentemente investida. Por eles mesmos" (p. 166).

Para se enfrentar a violência doméstica e familiar contra a mulher faz-se necessário considerá-la efetivamente como uma violência de gênero, em sua dimensão relacional, com suas marcações políticas, históricas e culturais, e não uma violência de sexo, restrita exclusivamente ao corpo e/ou à experiência de mulheres ou dos considerados "agressores".

Neste sentido, o problema da violência doméstica aponta para uma lógica dicotômica e contrastante, em que as ambiguidades e tensões nas relações de gênero estão presentes. Gregori (1993) defende a importância de tomar esses relacionamentos sem criar uma dualidade algoz-vítima, pois isso implicaria a ideia de um agressor ativo e um agredido passivo. Essa dualidade desconsidera que os padrões distintos de comportamento instituídos para homens e mulheres são atualizados nas relações interpessoais, que implicam combinações e ambigüidades, ou seja, diversidades. Conhecer as bases psicossociais sobre as quais se constroem as relações humanas é acrescentar mais um elemento para a compreensão deste fenômeno.

A partir dos depoimentos dos profissionais observa-se a necessidade de atentar para as especificidades das estratégias de intervenção voltadas para os homens de um modo geral e para aqueles envolvidos em episódios de violência contra a mulher, sobretudo no que concerne a estratégias de ressignificação simbólica dos próprios atores responsáveis pela intervenção.

A implantação de serviços de atenção aos homens autores de violência doméstica e familiar contra a mulher, mais do que uma "disputa de recurso público" - discurso utilizado por alguns profissionais, feministas e autoridades como forma de se posicionar contra essas ações - é, antes de tudo, uma estratégia de atender às necessidades demandadas pela maioria dos casos de violência, consistindo, como observa Grossi (2004), em uma intervenção positiva nos modelos de masculinidades, os quais, em nossa cultura, estão fortemente ligados à agressividade.

\section{REFERÊNCIAS}

Acosta, F., \& Barker, G. (2003). Homens, violência de gênero e saúde sexual e reprodutiva: um estudo sobre homens no Rio de Janeiro /Brasil. Rio de Janeiro: Instituto NOOS.

Arilha, M. (2005). O masculino em conferências e programas das Nações Unidas: para uma crítica do discurso de gênero. Tese de doutorado não publicada, Faculdade de Saúde Pública, Universidade de São Paulo, São Paulo, SP, Brasil. 
Bardin, L. (1977). Análise de conteúdo. Lisboa: Setenta.

Billig, M. (1987). Arguing and thinking: a rhetorical approach to social psychology. Cambridge, MA: Cambridge University Press.

Davies, B., \& Harré, R. (1990). Positioning: the discursive production of selves. Journal for the theory of social behaviour, 20(1), 43-63.

Debert, G. G., \& Gregori, M. F. (2008). Violência e gênero: novas propostas, velhos dilemas. Revista Brasileira de Ciência Sociais, 23(66), 165-211.

Gregori, M. F. (1993). Cenas e queixas: um estudo sobre mulheres, relações violentas e a prática feminista. São Paulo: Paz e Terra.

Grossi, M. (2004). Masculinidades: uma revisão teórica. Antropologia em Primeira Mão, 75 (1), 5-37.

Hanada H., D'Oliveira, A. F. P. L., \& Schraiber, L. B (2010). Os psicólogos na rede de assistência a mulheres em situação de violência. Revista Estudos Feministas, Florianópolis, 18(1), 3359.

Kiss, L., Schraiber, L., D’ Oliveira, A. (2007). Possibilidades de uma rede intersetorial de atendimento à mulher em situação de violência. Interface - comunicação, saúde, educação, São Paulo, 11(23), 485-501.

Medrado, B., \& Lyra, J. (2008). Por uma matriz feminista de gênero para os estudos sobre homens e masculinidades. Revista Estudos Feministas, 16(1), 809-840.

Medrado, B., \& Mello, R. P. (2008). Posicionamentos críticos e éticos sobre a violência contra as mulheres. Psicologia \& sociedade, Porto Alegre, 20(n. especial), 78-86.

Melo, Z. M., Silva, D. M., \& Caldas, M. T. (2009). Violência intrafamiliar: crimes contra a mulher na área metropolitana do Recife. Psicologia em Estudo, 14(1), 111-119.

Minayo, M. C. S. (Org.), (1999). Pesquisa social: teoria, método e criatividade. (13a ed). Petrópolis: Vozes.
Rifiotis, T. (2004). As delegacias especiais de proteção à mulher no Brasil e a "judiciarização" dos conflitos conjugais. Revista Sociedade e Estado, 19(1), 85-119.

Rorty, R. (1979). A Filosofia e o espelho da natureza. (A. Trânsito, Trad.). Rio de Janeiro: Relume Dumará.

Schraiber L. B., Barros, C. R. S., \& Castilho, E. A. (2010). Violência contra as mulheres por parceiros íntimos: usos de serviços de saúde. Revista Brasileira de Epidemiologia, 13(1), 237-245.

Schraiber, L. B., \& D'Oliveira, A. F. P. L. (2008). Violência contra mulheres e promoção dos direitos humanos: a contribuição do campo da saúde. Divulgação em Saúde para Debate, 58 (1), 110.

Schraiber, L. B., \& D'Oliveira, A. F. P. L; Falcão, N. T. C; Figueiredo,W. S. (2005) Violência dói e não é direito: a violência contra a mulher, a saúde e os direitos humanos. São Paulo: Ed. Unesp.

Schraiber, L. B., D’Oliveira, A. F. P. L., Portella, A. P., \& Menicucci, E. (2009). Violência de gênero no campo da Saúde Coletiva: conquistas e desafios. Ciência e saúde coletiva, 14(4), 1019-1027.

Schraiber, L. B., D'Oliveira, A. F. P. L., \& Couto, M.T. (2009). Violência e saúde: contribuições teóricas, metodológicas e éticas de estudos da violência contra a mulher. Cadernos de Saúde Pública, 25 (1), S205-S216.

Spink, M. J. P., \& Medrado, B. (1999). Produção de sentido no cotidiano: Uma abordagem teórico-metodológica para análise das práticas discursivas. In M. J. P. Spink (Org.), Práticas Discursivas e Produção de Sentidos no Cotidiano: Aproximações Teóricas e Metodológicas (pp. 41-61). São Paulo: Cortez.

Recebido em 21/08/2011 Aceito em 07/11/2011

\section{Endereço para correspondência:}

Benedito Medrando. Rua Mardônio Nascimento, 129, CEP 50.741-380, Recife-PE, Brasil. Email: beneditomedrado@gmail.com. 